\title{
The Preliminary Study of Applying TOPSIS Method to Assess an Elderly Caring Center Performance Ranking
}

\author{
Liao Ling-Chu* \\ Department of Accounting, Shih Chien University, Taipei City, Taiwan \\ *Corresponding author: lingchu@g2.usc.edu.tw
}

\begin{abstract}
It is most important to evaluate performance between profit and not-profit organizations. Profit-"the bottom line"-is an unambiguous measure of a business organization's effectiveness. Not-for-profit organizations make performance measurement more difficult. However, we do not think this means that managers in those organizations can ignore finances for continuous operating. The study analyze ten successive years nonfinancial and financial information variables of the case elderly caring center, ranking surface reflectivity can help the strategic decision-making. Using TOPSIS method as based on financial and nonfinancial information of ten consecutive years for an elderly caring center to examine past performance and systematically exploring alternative ways to make better-informed decisions in the future. The results indicate based on the comparison among of the ten years, performance ranking from the first to sixth are respectively 2013, 2011, 2014, 2015, 2016, and 2011. Among the ten years, there are four years (e.g. 2007, 2012, 2013, and 2016) are as excellent by the government in Taiwan. The elderly caring center also has good execution efficiency in accordance with budgets at the end of year. As an "excellent" elderly caring center should has a unique operational pattern and TOPSIS is very usefully to support organizational strategic decision-making.
\end{abstract}

Keywords: TOPSIS method, elderly caring center, performance ranking

Cite This Article: Liao Ling-Chu, "The Preliminary Study of Applying TOPSIS Method to Assess an Elderly Caring Center Performance Ranking." Journal of Business and Management Sciences, vol. 6, no. 1 (2018): 22-27. doi: 10.12691/jbms-6-1-5.

\section{Introduction}

Population aging is a global trend of the $21^{\text {st }}$ century, as the global society has gradually become an ageing society, governments and enterprises are very aggressiveness in elderly nursing and caring services in the Taiwan. From the international development of elderly welfare policies, the United Nations has confirmed health and welfare as two major issues relevant to the elderly. The World Health Organization put forward the core values of "Active Ageing” in 2002 [1]. In order to promote the living quality of elders that must be consider the Optimized of health, participation, and safety to enhance ageing becoming into a positive experience. This is also the main reference structure for international organizations to formulate health policies for the elderly. In 2013, Taiwan's Ministry of Health and Welfare pointed out with the progress of health care, the average life expectancy and birth rate decreased significantly. Taiwan's elderly people is up to $7 \%$ of the total population in 1993, officially entered the aging society defined by the United Nations, until the end of October 2013, this proportion had reached 11.43\%. According to the statistical data published by the Ministry of the Interior on April 9, 2017, the number of the elderly reached 313,9000 on February, exceeding of children less than 14 years old $(313,4000)$ for the first time, and the ageing index was 100.18, higher than 100 for the first time.
The Council for Economic Planning and Development, Executive Yuan was estimated that the number would be exceed 14\% turning into “Aged Society” in 2018. Further, the number will be exceed $20 \%$ again in 2025, then turning into "Supper Aged Society" [2]. Taiwan's population structure is confronted by two challenges overall: first, the future ageing speed is higher than European countries and the U.S.; second, the ratio of the function of elderly caring for by family members has been decreased. Thus, the government enhanced their guarantee to protect elderly economic safety by the national pension system; about the elders lacking self-caring capability supported by Taiwan's 10-year long-term care plan in current. Taiwan's Long-term Caring Service Law was examined and approved by the Legislative Yuan on June in 2015, and fully and formally implemented in 2017. The Ministry of Health and Welfare formulated the sub-laws and sub-regulations, planned relevant support measures, spared no efforts to promote the " 10 -year long-term care plan 2.0", accelerated the development of long-term service resources, and generalized long-term care services. Moreover, it checked resources, combined with civilian power, and actively expanded the diversified care service mode in communities to cope with the demands of an ageing society. In Taiwan, the elderly welfare organizations consist of long-term nursing organizations and elderly caring institutions. The former can be classified into elderly long-term care institutions, elderly nursing institutions, and elderly dementia care institutions, 
the latter provides nursing and caring services. Long-term nursing organizations provided the services of the elderly with long-term chronic diseases and require health care, and care for the elderly that lack self-help abilities or the elderly requiring nasogastric tubes and catheter care services. Elderly dementia care institutions care for the elderly diagnosed as more than moderate dementia by specialists, such as physicians of neurology and psychiatry departments, meaning they are able to act but require caring. Elderly caring institutions care for the elderly requiring others' care, those who do not have relatives with the duty to support them, or whose relatives with the duty to support do not have the ability to support them, and who can take care of themselves. According to the statistics of the Ministry of Health and Welfare on April 30 in 2017, the total number of elderly long-term nursing organizations and long-term care institutions were 1085, and total number of people was 61,425 , actually had been lived 47,275 people, it reached $77 \%$ of the total number of people. Let us know the view that the elderly are very willing to live there [3].

The Ministry of Health and welfare is a welfare institution that manages domestic issues for the elderly; according to the Elderly Welfare Law -Article 3, the central governing authority holds an evaluation at least once every three years that the evaluation aims are promoted the business development and operational management concepts of elderly welfare institutions, enhanced service quality to ensure the elderly can acquire the overall services from the institution. Elderly welfare organizations became a social trend, which confronted with operational revolution and innovation orientation [4]. It is an import issue that the organizations how to provide professional experience for elders, follow the standards under governing authority's evaluation, and achieve operational management objectives

The term of performance refers to the degree of achieved specific business goals. The purpose of performance evaluation is to measure actual performance in order to inform managers of how well they and their sub-units are doing. Linking both intrinsic and extrinsic rewards to performance helps motivate managers. For the nonprofit care organization industry, improving operating performance has always been the goal of management. Thus, the problem involves multi-criteria, multi-project, multi-personal, and multinational considerations, which all are a part of multi-criteria decision making (MCDM). Elderly welfare organizations must provide long-term care and professional services for the elderly, thus, what key success factors are needed in order to provide such services in a competitive industry, meaning sustaining maintenance of national communities, while considering cost management and operational performance The process should satisfy multiple criteria, as well as address alternatives and varying opinions. Therefore, although difficult, how to achieve operating performances that support the best services for elderly care organizations is an important issue.

The aimed of this study used TOPSIS method to analyze ten successive years' nonfinancial and financial information variables of the case elderly caring center. Ranking surface reflectivity can help their strategic decision making.

\section{Materials and Method}

The subjects of this study is elderly caring center that operate caring service in northern Taiwan. This study took elderly caring center established since 2000 for the first stage, the second stage since 2003, then 2009, and until now. The center are near both mountains and beach, which provide surroundings with beautiful scenery, peace, and tranquility. This study also selects elderly caring center that provide dementia care division (unit care), an elderly community college, an eldercare research center, a community care station, home care, mission centers, etc. Due to the highly professional performances of the case elderly center, the current waiting list has more than a thousand people. In order to give the most perfect attendance and sincerity service to the complete care to elders, the center has hired professional persons to take care of them, provides medical clinic services, varied classes, and spiritual counseling. By combining varied functions in the center, and cooperating with industry, government, and academic institutions, it strives to integrate academic professional knowledge and experience to creating satisfactory services to elders, and meet their daily living needs to realize the care of elder citizens.

\subsection{Statistical Analysis of Data}

The decision makers of this study were government agencies, experts, academic scholars, and management of the case elderly caring center. There were different eight nonfinancial and financial criteria, nonfinancial criteria including Number of employee and Number of service; financial criteria including operating revenue, expenditure, salary and wage, operating income, government subsidy, and capital expenditure was shown in Table 1 . The statistical description analysis and correlation analysis of all variables were shown in Table 2 and Table 3.

Table 1. Definitions of performance criteria of the case elderly caring center

\begin{tabular}{|c|l|c|l|}
\hline & Performance criteria & Code & Definitions of criteria \\
\hline \multirow{3}{*}{ Non-fc. } & Number of employee & No. E & Number of employee is the hiring staff of the elderly center \\
\cline { 2 - 4 } & Number of service & No. S & Number of service is the service elders in the elderly center \\
\hline \multirow{5}{*}{ Fc. } & Operating revenue & OR & Operating revenue is the service revenue from caring elders \\
\cline { 2 - 4 } & Expenditure & E & Expenditure is the regular expenses in the operating process, excluding salary and wage \\
\cline { 2 - 4 } & Salary and wage & SW & Salary and wage are the reimbursement of Employees \\
\cline { 2 - 4 } & Operating income & OI & Operating income is the residual of deducting operating cost from Operating revenue \\
\cline { 2 - 4 } & Government subsidy & GS & Government subsidy is a reward and grant from local or government \\
\cline { 2 - 4 } & Capital expenditure & CE & Capital expenditure is the expenditure of making long-run planning decision for investments \\
\hline
\end{tabular}

Note: ${ }^{*}$ Non-fc.: Nonfinancial criteria, ${ }^{* *}$ fc.: financial criteria. 
Table 2. The statistical description analysis of all variables

\begin{tabular}{|c|c|c|c|c|c|c|c|c|}
\hline & No. E & No. S & OR & E & SW & OI & GS & CS \\
\hline Min. & 122.00 & 366.00 & $137,412.00$ & $2,797.00$ & $109,505.00$ & $67,793.00$ & $8,959.00$ & $2,318.00$ \\
\hline Man. & 196.00 & 432.00 & $199,418.00$ & $17,309.00$ & $186,133.00$ & $129,063.00$ & $30,543.00$ & $37,435.00$ \\
\hline Average & 169.00 & 412.20 & $174,094.40$ & $10,202.20$ & $153,042.30$ & $100,903.40$ & $21,052.30$ & $10,744.80$ \\
\hline Std. & 31.58 & 31.88 & $26,412.02$ & $4,374.18$ & $29,676.10$ & $23,188.69$ & $7,057.19$ & $10,431.56$ \\
\hline
\end{tabular}

Table 3. The correlation analysis of all variables

\begin{tabular}{|c|c|c|c|c|c|c|c|c|}
\hline & No. E & No. S & OR & E & SW & OI & GS & CS \\
\hline No. E & 1 & $0.983^{* *}$ & $0.938^{* *}$ & $0.701^{*}$ & $0.965^{* *}$ & $0.976^{* *}$ & -0.548 & -0.516 \\
\hline No. S & $0.803^{* *}$ & 1 & $0.870^{* *}$ & $0.689^{*}$ & $0.908^{* *}$ & $0.925^{* *}$ & -0.564 & -0.464 \\
\hline OR & $0.976^{* *}$ & $0.798^{* *}$ & 1 & $0.739^{*}$ & $0.975^{* *}$ & $0.971^{* *}$ & -0.357 & -0.528 \\
\hline E & 0.591 & $0.722^{*}$ & 0.612 & 1 & $0.638^{*}$ & $0.649^{*}$ & 0.084 & -0.033 \\
\hline SW & $0.994^{* *}$ & $0.798^{* *}$ & $0.988^{* *}$ & 0.600 & 1 & $0.995^{* *}$ & -0.556 & -0.535 \\
\hline OI & $0.994^{* *}$ & $0.798^{* *}$ & $0.988^{* *}$ & 0.600 & $1.000^{* *}$ & 1 & -0.550 & -0.551 \\
\hline GS & -0.530 & -0.494 & -0.479 & 0.103 & -0.527 & -0.527 & 1 & 0.273 \\
\hline CS & $-0.639^{*}$ & -0.267 & $-0.644^{*}$ & -0.055 & -0.620 & -0.620 & 0.195 & 1 \\
\hline
\end{tabular}

Note: 1 . The upper right corner is Pearson correlation analysis, the lower left corner is the Spearman rank correlation analysis.

$$
\text { 2.*: } \mathrm{p}<0.05, * *:<0.01 \text {. }
$$

TOPSIS is a performance evaluation tool successfully applied to many kinds of research such as environmental quality improvement strategies [5], alternative-fuel buses for public transportation [6], large project solutions [7], customer-driven product design processes [8], evaluating the competitive advantage of shopping websites [9], supplier evaluation and selection [10,11], evaluation of the performance of property liability insurance companies [12], evaluation of expressway bus transportation performance [13], evaluating initial training[14], ocean freight forwarder [15], calling port of a case shipping company [16], and elderly welfare institutions [17]. Thus, our study consider using TOPSIS to rank the performance of a case of elderly caring center.

Sun and Lin (2009) pointed out we should follow six steps when using TOPSIS method as follow [9].

(1) Calculate the normalized decision matrix. The normalized value $r_{i j}$ is calculated as

$$
R=\left[\begin{array}{cccccc}
r_{11} & r_{12} & \ldots & r_{1 j} & \ldots & r_{1 n} \\
r_{21} & r_{22} & \ldots & r_{2 j} & \ldots & r_{2 n} \\
\ldots & \ldots & \ldots & \ldots & \ldots & \ldots \\
r_{i 1} & r_{i 2} & \ldots & r_{i j} & \ldots & r_{i n} \\
\ldots & \ldots & \ldots & \ldots & \ldots & \ldots \\
r_{m 1} & r_{m 2} & \ldots & r_{m j} & \ldots & r_{m n}
\end{array}\right]
$$

(2) Calculate the weighted normalized decision matrix. The weighted normalized value $V$ is calculated as

$$
V=\left[\begin{array}{cccccc}
w_{1} r_{11} & w_{2} r_{12} & \ldots & w_{j} r_{1 j} & \ldots & w_{n} r_{1 n} \\
w_{1} r_{21} & w_{2} r_{22} & \ldots & w_{j} r_{2 j} & \ldots & w_{n} r_{2 n} \\
\ldots & \ldots & \ldots & \ldots & \ldots & \ldots \\
w_{1} r_{i 1} & w_{2} r_{i 2} & \ldots & w_{j} r_{i j} & \ldots & w_{n} r_{i n} \\
\ldots & \ldots & \ldots & \ldots & \ldots & \ldots \\
w_{1} r_{m 1} & w_{2} r_{m 2} & \ldots & w_{j} r_{m j} & \ldots & w_{n} r_{m n}
\end{array}\right]
$$

Where $w=\left(w_{1}, w_{2}, \ldots \ldots, w_{n}\right)$ is the weight of the ith attribute or criterion and

$$
\sum_{j=1}^{n} w_{j}=1
$$

(3) Determine the ideal and negative-ideal solution.

$$
\begin{aligned}
& A^{+}=\left\{\begin{array}{l}
{\left[\begin{array}{lll}
\max _{i} & v_{i j} & j \in J], \\
{\left[\min _{i}\right.} & v_{i j} & j \in J^{\prime}
\end{array}\right] \mid I=1,2, \ldots, m}
\end{array}\right\} \\
& =\left(\begin{array}{llllllll}
v_{1}^{*}, & v_{2}^{*}, & \ldots & v_{j}^{*} & , & \ldots & , v_{n}^{*}
\end{array}\right) \\
& A^{-}=\left\{\begin{array}{l}
{\left[\begin{array}{lll}
\min _{i} & v_{i j} & j \in J], \\
{\left[\max _{i}\right.} & v_{i j} & j \in J^{\prime}
\end{array}\right] \mid I=1,2, \ldots, m}
\end{array}\right\} \\
& =\left(\begin{array}{llllllll}
v_{1}^{-} & , v_{2}^{-} & , & \ldots & , & v_{j}^{-} & \ldots & , v_{n}^{-}
\end{array}\right) \\
& j=1,2, \ldots, n
\end{aligned}
$$

(4) Measure the separation of alternatives from the ideal solutions. The separation of each alternative from the ideal solution is given as

$$
S_{i}^{+}=\sqrt{\sum_{j=1}^{n}\left(v_{i j}-v_{j}^{*}\right)^{2}}, i=1,2, \ldots, m
$$

Similarly, the separation from the negative ideal solution is given as

$$
S_{i}^{-}=\sqrt{\sum_{j=1}^{n}\left(v_{i j}-v_{j}^{-}\right)^{2}}, i=1,2, \ldots, m
$$

(5) Calculate the relative closeness of each alternative to the ideal solution. The relative closeness of the alternative is defined as

$$
C_{i}=\frac{S_{i}^{-}}{S^{+}+S_{i}^{-}}
$$




$$
0<C_{i}^{+}<1, i=1,2, \ldots, m .
$$

(6) Finally, rank the preference order.

\section{Result}

The decision makers measured the relative importance weight of each criteria, which are summarized in Table 4. The data is shows that the most important criteria in evaluating performance is Expenditures, Operating revenues, and Operating income, indicating that revenue and cost factors absolutely determine the benefits of elderly care center. The normalized decision matrix used by Equation (1) is shown in Table 5.

The weighted normalized decision matrix used by Equation (2) is shown in Table 6.

For determining the ideal and negative-ideal solutions, the study utilizes Equations (3) and (4), with the results are shown as follows.

$$
\begin{aligned}
& A^{+}=\left\{\begin{array}{llll}
0.0136, & 0.0065, & 0.0206, & 0.0204, \\
0.0300, & 0.0183, & 0.0107, & 0.0202
\end{array}\right\} \\
& A^{-}=\left\{\begin{array}{llll}
0.0084, & 0.0055, & 0.0142, & 0.0033 \\
0.0177, & 0.0096, & 0.0031, & 0.0013
\end{array}\right\}
\end{aligned}
$$

We subsequently employed Equations (5) and (6) to calculate the separation of each alternative solution from the ideal solution, as demonstrated in Table 7.

Following Equation (7) is shown in Table 8 which indicating the operating performances of 2013, 2011, 2012, 2016, 2014, and 2015 were respectively ranked from first to sixth that may be considered to be the best maximizing of the expected performance, in this case of elderly care center, to concentrate its operating resources and strengthen its implemented strategy.

Table 4. The weight of each criteria

\begin{tabular}{|c|c|c|c|c|c|c|c|c|}
\hline & No. E & No. S & OR & E & SW & OI & GS & CS \\
\hline Weight & 0.17 & 0.062 & 0.180 & 0.120 & 0.247 & 0.143 & 0.074 & 0.058 \\
\hline
\end{tabular}

Table 5. The analyzing results of normalized decision matrix

\begin{tabular}{|c|c|c|c|c|c|c|c|c|}
\hline Year & No. E & No. S & OR & E & SW & OI & GS & CS \\
\hline 2007 & 122 & 366 & 140048 & 4873 & 109505 & 67793 & 30543 & 5046 \\
\hline 2008 & 125 & 366 & 137412 & 2797 & 114149 & 70308 & 23263 & 10818 \\
\hline 2009 & 125 & 366 & 144915 & 9829 & 118266 & 71341 & 26649 & 37435 \\
\hline 2010 & 177 & 432 & 156279 & 7034 & 147320 & 98410 & 8959 & 14016 \\
\hline 2011 & 183 & 432 & 180680 & 17309 & 153743 & 102385 & 26937 & 13585 \\
\hline 2012 & 184 & 432 & 187915 & 11790 & 166907 & 112582 & 21008 & 12232 \\
\hline 2013 & 192 & 432 & 197165 & 14998 & 170209 & 117080 & 26957 & 5782 \\
\hline 2014 & 193 & 432 & 198318 & 11216 & 180494 & 119151 & 17824 & 3898 \\
\hline 2015 & 193 & 432 & 198794 & 10803 & 183697 & 120921 & 15098 & 2318 \\
\hline 2016 & 196 & 432 & 199418 & 11373 & 186133 & 129063 & 13285 & 2318 \\
\hline
\end{tabular}

Table 6. The analyzing results of weighted normalized decision matrix

\begin{tabular}{|c|c|c|c|c|c|c|c|c|}
\hline Year & No. E & No. S & OR & E & SW & OI & GS & CS \\
\hline 2007 & 0.0722 & 0.0888 & 0.0804 & 0.0478 & 0.0716 & 0.0672 & 0.1451 & 0.0470 \\
\hline 2008 & 0.0740 & 0.0888 & 0.0789 & 0.0274 & 0.0746 & 0.0697 & 0.1105 & 0.1007 \\
\hline 2009 & 0.0740 & 0.0888 & 0.0832 & 0.0963 & 0.0773 & 0.0707 & 0.1266 & 0.3484 \\
\hline 2010 & 0.1047 & 0.1048 & 0.0898 & 0.0689 & 0.0963 & 0.0975 & 0.0426 & 0.1304 \\
\hline 2011 & 0.1083 & 0.1048 & 0.1038 & 0.1697 & 0.1005 & 0.1015 & 0.1280 & 0.1264 \\
\hline 2012 & 0.1089 & 0.1048 & 0.1079 & 0.1156 & 0.1091 & 0.1116 & 0.0998 & 0.1138 \\
\hline 2013 & 0.1136 & 0.1048 & 0.1133 & 0.1470 & 0.1112 & 0.1160 & 0.1280 & 0.0538 \\
\hline 2014 & 0.1142 & 0.1048 & 0.1139 & 0.1099 & 0.1179 & 0.1181 & 0.0847 & 0.0363 \\
\hline 2015 & 0.1142 & 0.1048 & 0.1142 & 0.1059 & 0.1200 & 0.1198 & 0.0717 & 0.0216 \\
\hline 2016 & 0.1160 & 0.1048 & 0.1145 & 0.1115 & 0.1216 & 0.1279 & 0.0631 & 0.0216 \\
\hline
\end{tabular}

Table 7. The separation measure of each alternative solution from the ideal solution

\begin{tabular}{|c|c|c|c|c|c|c|c|c|c|c|}
\hline Year & 2007 & 2008 & 2009 & 2010 & 2011 & 2012 & 2013 & 2014 & 2015 & 2016 \\
\hline$S_{i}^{+}$ & 0.0654 & 00.0663 & 0.0408 & 0.0487 & 0.0260 & 0.0309 & 0.0258 & 0.0324 & 0.0339 & 0.0320 \\
\hline$S_{i}^{-}$ & 0.0118 & 0.0109 & 0.0363 & 0.0285 & 0.0512 & 0.0463 & 0.0513 & 0.0448 & 0.0433 & 0.0452 \\
\hline
\end{tabular}

Table 8. TOPSIS ranking list of each alternative

\begin{tabular}{|c|c|c|c|c|c|c|c|c|c|c|}
\hline Year & 2007 & 2008 & 2009 & 2010 & 2011 & 2012 & 2013 & 2014 & 2015 & 2016 \\
\hline$C$ & 0.1525 & 0.1416 & 0.4709 & 0.3691 & 0.6633 & 0.5996 & 0.6652 & 0.5806 & 0.5614 & 0.5854 \\
\hline Ranking & 9 & 10 & 7 & 8 & 2 & 3 & 1 & 5 & 6 & 4 \\
\hline
\end{tabular}




\section{Conclusion}

The aimed of this study used TOPSIS method analyzing performance of a case elderly care center regarding their nonfinancial and financial information variables of ten successive years. Ranking surface reflectivity can help in making strategic decision. The results indicate based on the comparison among of the ten years, performance ranking from the first to sixth are respectively 2013, 2011, 2014, 2015, 2016, and 2011. Among the ten years, there are four years (e.g. 2007, 2012, 2013, and 2016) are as excellent by the government in Taiwan. Although 2007 and 2010 are not among the top sixth performance ranking, also receiving "excellent". The elderly caring center also has good execution efficiency in accordance with budgets at the end of year. Owing to the management efforts to expand their financial sources, the no-operating revenues have been increasing year by year, and the acquiring of personnel allowance from the government also encourage increased employment and reduce financial burden.

The elderly nursing and caring services has turned from relief and resettlement to silver industry, and from welfare service, free competition market turn into business management orientated pattern. There are the success factors of elderly nursing and caring institution operations has six factors, such as operation concept, work group, resources, professional services, institution head, and location selection [18]. Facing the changing, competing, and demands, nursing organizations and elderly caring institutions should be applying the key success factors of cost and efficiency, quality, time, and innovation to promote sustainable to achieve long-term financial social, and environmental goal. This paper investigated and learned with the results of ten years of nonfinancial and financial information of the case elderly caring center, which involves examining past performances and systematically exploring alternative ways to make better-informed decision and plan for the future. With the increasing of the aging society, the silver group has more and more demands for elderly nursing and caring institution services. Concentration ratio, service capacity of the elderly population, number of elderly people, and per capita income (dollars) are the factors that affect the operating efficiency of the nursing and elderly caring organization. Areas with a high concentration ratio and the higher service capacity of the elderly population that can be served by the nursing home all belong to or tend to be oligopoly market and have a negative impact on operational performance [19]. When setting up an elderly caring organization, management not only need to refer the number of elderly people in the area and the number of nursing and elderly caring organization, but also consider market attributes in order to avoid too concentrated industrial resources and cause a strong resource crowding-out effect. In areas where the more elderly serve and the lower market concentration (higher competition degree), a positive effect for operational performance. Under the lack of concentration of industrial resources, nursing and elderly caring organization may can develop strategic alliances with other nursing and elderly caring organization, to enhance diversified services, flexibility adjustment, timely, and provide more promotion for the demands.
As an "excellent" of the case elderly caring center, regarding operational concepts and financial scales has a unique operational pattern. They must be consistently to improve the service quality and competitive advantage. In the operating process, comply with the philosophy, practices, value of the organization and accordance with the rule of government authority to enhance the corporate social responsibilities. This study also concludes that TOPSIS is a usefully tool for evaluation performance and supporting organizational strategic decision-making.

\section{References}

[1] WHO. (2002) .Active Ageing: A Policy Framework Pages 1-37. Published online: 06 Jul 2009.

[2] Ministry of Health and Welfare, Taiwan. (2017). 2017 Local Health Authorities Operation Assessment Manuals. Available at: https://www.mohw.gov.tw/dl-1223-425b2376-c374-4af5-933b56622ec197b8.html.

[3] Ministry of Health and Welfare, Taiwan. 2013. Friendly care for the elderly service program. Available at: http://www.ey.gov.tw/Upload/RelFile/27/.../a4ca6e69-4eb6-4f0a967e-ea8ef114d029.pdf.

[4] Ministry of Health and Welfare, Taiwan. (2015). No. BSJZD 1040800499. Available at: http://www-ws.pthg.gov.tw/Upload/2015pthg/18/ckfile/2c4d8701e084-40f3-93e3-f2e62dc0a396.pdf.

[5] Tzeng, G. H., Tsaur, Y. D., Laiw, Y. D., and Opricovic. S. (2002). Multicriteria analysis of environmental quality in Taipei: Public performance and improvement strategies. Journal of Environmental Management, 65 (2), 102-120.

[6] Tzeng, G. H., Line, C. W., and Opricovic. S. (2005). Multi-criteria analysis of alternative-fuel buses for public transportation. Energy Policy, 33 (11), 1373-1383.

[7] Mahmoodzadeh, S., Shahrabi, J., Pariazar, M., and Zaeri. M. S. (2007). Project selection by using AHP and TOPSIS technique. World Academy of Science. Engineering and Technology, 30, 270-275.

[8] Lin, M. C., Wang, C. C., Chen, M. S., and Chang. C. A. (2008). Using AHP and TOPSIS approaches in customer-driven product design process. Computers in Industry, 59 (1), 17-31.

[9] Sun, C. C., and Lin, G. T. R. (2009). Using fuzzy TOPSIS method for evaluating the competitive advantage of shopping websites. Expert Systems with Applications, 36 (9), 00764-00771.

[10] Pi, W.N. (2005). Supplier Evaluation Using AHP and TOPSIS. Journal of Science and Engineering Technology, 1 (1), 75-83.

[11] Wang, J. W., Cheng, C. H., and Hang, K. C. (2009). Fuzzy hierarchical TOPSIS for supplier selection. Applied Soft Computing, 9 (1), 377-386.

[12] Tsai, H. Y., Huang, B. H., and Wang. A. S. (2008). Combining ANP and TOPSIS concepts for evaluation the performance of property liability insurance companies. Journal of Science Social, 4 (1), 56-61.

[13] Chang, H. G., Wang, K. Y., and Lin, S.Y. (2011). Expressway Bus Transportation Performance Evaluation: Using TOPSIS Approach. ICIC Express Letters, 5 (11), 4065-4069.

[14] Wang, T. C., and Chang, T. H. (2007). Application of TOPSIS in evaluating initial training aircraft under a fuzzy environment. Expert System with Applications, 33 (4), 870-880.

[15] Liao, L. C. (2013). Evaluating Ocean Freight Forwarder Performance: A Case Study. Annual Quality Congress Transactions, 1, 13-21.

[16] Liao, L. C. (2017). Analyzing the Strategic Performance of Calling Port $\mathrm{n}$ A Case Shipping Company Based on TOPSIS. International Review of Social Sciences, 5 (6), 333-343.

[17] Wang, C. H., Chen, P. C., and Huang. H. C. (2011). Health care efficiency and determinants-A comparison of Taiwan and OECD countries. Journal of Information and Optimization Sciences, 32 (1), 213-231.

[18] Chen, L. K. (2005). Analysis on key success factors of operation management of elder care institution in Taiwan. Community Development Journal, 110, 250-259. 
[19] Chang, S. J., Lu, W. M., and Deng, Y. C. (2013). The Efficiency Evaluation of Seniors Housing-The Comparison Between the
Veteran Home and Public (Private) Nursing home. SOOCHOW JOURNAL OF ACCOUNTING, 5 (1), 27-59. 